Article

\title{
Living in the "Ghost City": Media Discourses and the Negotiation of Home in Ordos, Inner Mongolia, China
}

\author{
Duo Yin ${ }^{1,2}$, Junxi Qian ${ }^{3}$ and Hong Zhu ${ }^{1,2, *}$ \\ 1 Centre for Cultural Industry and Cultural Geography, South China Normal University, \\ Guangzhou 510631, China; yinduo@m.scnu.edu.cn \\ 2 School of Geography, South China Normal University, Guangzhou 510631, China \\ 3 Department of Geography, The University of Hong Kong, Pokfulam Road, Hong Kong, China; \\ jxqian@hku.hk \\ * Correspondence: zhuh@scnu.edu.cn; Tel.: +86-20-8521-1896
}

Received: 8 August 2017; Accepted: 3 November 2017; Published: 6 November 2017

\begin{abstract}
Ordos is notoriously represented in media discourses as one of China's principal "ghost cities", with skyscrapers, apartment estates and grandiose squares largely unoccupied. The "ghost city" emerges from massive (over)investment in the urban built environment. Aware that economic and financial sustainability are in question, we nonetheless choose to investigate this issue from the perspective of social sustainability, utilizing a theoretical framework informed by geographies of home. Relatively little analysis has thus far been applied to local residents' everyday practice and agency in making place and home in allegedly "unhomely" ghost cities. This article first examines media discourses and representations of the "ghostly" aspect of the new town in Ordos. It then investigates the ways in which local residents practice and perform their place identity and sense of home in an alleged "ghost city". Our empirical research in Kangbashi New Town demonstrates that the discourse of ghost cities is valid in so far as we take into account the local residents' engagement in a process of home-making from below. This sense of place is created by connecting new and old homes, and constructing an emotionally delineated place identity. We argue that the issue of social sustainability in Ordos is multifaceted, and more nuanced than it has hitherto been represented in media reports.
\end{abstract}

Keywords: ghost city; media discourse; everyday practice; home; Ordos

\section{Introduction}

This article seeks to address media and public debates on "ghost cities" from the perspective of social sustainability, providing a grounded and nuanced understanding of residents' everyday practices and agency in making home. Our analysis is also a response to the discourses of "ghost cities" produced by the media. The "ghost city" terminology originated from two renowned international media outlets, namely, Al Jazeera and Time magazine, which uncritically presented Kangbashi New Town in Ordos, China, as an exemplar of a ghost city and epitome of uncontrolled and unsustainable methods of new town development [1]. In recent years, so-called "ghost cities" have sprung up in the midst of dramatic new town development projects in China. Considered to be engineered by the modernization and urbanization schemes of the Chinese state, ghost cities have elicited widespread controversies both in China and abroad. Media discourses of ghost cities have so far centred mainly on rapid urban construction driven by local governments in the pursuit of various growth-oriented benefits, usually ending up with scantly populated and largely unoccupied skyscrapers, apartment estates and grandiose squares. As Woodworth and Wallace have argued, a ghost city in the Chinese 
context consists of "large-scale urban areas, sometimes planned as new towns, featuring an abundance of new built space and appearing to also have extremely low tenancy" [1]. Many academic studies have unproblematically absorbed media discourses of ghost cities to describe the status quo of China's new towns [2], while obfuscating the fact that new towns are ongoing dynamics of change and becoming. In this thread of scholarship, different types of new towns have been taken as points of entry to examine the political-economic logics of state-led urbanization strategies in the formation of ghost cities in China, with an emphasis on issues of economic and financial sustainability. These scholars assert that the problem of Chinese ghost cities is tied to rapid and over-ambitiously planned development of the real estate sector [3] and driven by local political players' ambition to control cities' land as a commodity [4]. Due to the lack of official statistics on urban tenancy and vacancy, studies have sought to construct indicators and models that reflect wasteful and inefficient uses of urban construction land [5].

However, some scholars have questioned the usefulness of macrospatial political economic perspectives and instead evaluated the social sustainability of new towns [6]. For example, Chen focuses on the sociocultural dimensions of the current situation in ghost cities [7]. He clarifies that the purchase of houses for investment, the distance from main urban areas, and the lack of essential infrastructure are the most common causes of urban vacancy [8]. Chi et al. also note that the media's reliance on night light situations as the sole evidence of the existence of ghost cities is not accurate. Alternatively, employing Baidu positioning data, they use Kangbashi as a case study to analyse the dynamics of population change in so-called "ghost cities". The results show that the population density and use of space in ghost cities fluctuate periodically over time [9]. The situation in Kangbashi is more complex and diverse than media reports have monolithically portrayed. These studies provide an intellectual context for understanding the emergence and proliferation of urban districts and spaces that are allegedly alienated from the established sociocultural fabrics of cities. Relatively less effort, however, has thus far been dedicated to meticulously unpacking ghost city residents' everyday life and their efforts to make a home.

Social sustainability involves promoting social harmony, avoiding social dysfunction, and improving the quality of life of the population [10]. While aware that economic and financial sustainability are certainly in question in analyses of ghost cities, we nonetheless choose to investigate this issue from the perspective of social sustainability, utilizing a theoretical framework informed by geographies of home. "Home" is a complex and rich concept, which in geographical research not only denotes material and concrete space, such as houses, apartments and other "physical material and concrete locations", but also carries the symbolic meanings and imaginations produced by various social groups [11]. Whether analysed as material or symbolic, home is not only a fixed and concrete entity but more importantly an unconscious, constantly unfolding and socially constructed practice negotiated by people who share similar sentiments in certain places [12]. Day-to-day practice is essential to understanding ordinary people's making of homes [13]. Shove, Pantzar, and Watson argue that a scheme of practice includes materials (e.g., infrastructures, tools and even the body), competence (e.g., know-how and appropriate performance) and meaning (e.g., motivation and experience to attend a practice) [14]. These three aspects constitute a useful analytical framework for practice [15]. In this paper, we focus on the practice of home-making, which Blunt and Dowling have defined as "the processes that actively and continuously produce 'home' and embed people in the landscape" [16]. The ongoing process of (re-)making a homely place consists of building an emotional connection with a significant place [17], and central to this connection are the ways in which individuals perform belonging and identity related to specific places [18]. As Massey argues [19], an individual can emotionally conceive more than one place as home, and each such place is a constellation of multiple temporal layers of social relations. The sense of home is developed in different places at different times that are linked together by everyday practices. Kochan, for example, has found that, in the context of China, migrants construct sense of home, identity and place attachment mainly through mobility, flexibility and home change [20]. This process involves their practice and negotiation of home in both 
old homes (lao jia) and new homes. Especially in social contexts where migration and mobility are increasingly the norm, we need a comprehensive and dynamic view of home-making and should pay attention to the lived practices and negotiation of everyday life in places of relocation [21].

The cultural-spatial logics of home, as sketched above, are evident in the home-making processes in the new towns that are now prevalent in China. To begin with, media discourses of ghost towns, while usefully pointing to issues of overinvestment and inflation of financial capital, should not be readily and unquestioningly accepted in cultural terms. While the concentration of unsold properties and underused public infrastructures exist in these cities-in-waiting, it is nonetheless necessary to understand how these landscapes are inhabited by people who have already moved in, through the lens of daily practices rather than a rigid epistemological distinction between the ghostly and the vibrant. Meanwhile, rapid urbanization and unprecedented mobility amidst China's urban transition pose challenges to individuals' experience and negotiation of different places [22]. Once they have moved to new towns, residents are not always negative recipients of the meanings of "un-home" but capable of manipulating local resources to construct an emergent sense of home. These bottom-up processes of everyday negotiation are essential to the sustainable development of place and place-based social cohesiveness [23]. More research, in this sense, is needed to explore the way in which new town residents construct their home (in both material and symbolic ways) and to interpret the spatial-temporal changes wrought by the development of new towns.

The empirical study described in this paper supplies two major findings that lend credence to our argument. Overall, we are interested in how mainstream representations and images of ghost cities are produced in public discourses and how the unhomely aspects of the "ghost cities" co-exist with local residents' endeavours of home-making. To investigate this issue, we present empirical research from Kangbashi New Town, the epitome of China's ghost cities, on which many media reports are based. First, we argue that, while media discourses reflectively and correctly criticized China's state-driven urbanism based on massive capitalization and financialization, the ghostly and exotic image of Kangbashi is necessarily partial and cannot be taken at face value. Second, we further argue that the discourses of the unhomely, as propagated by the media, are valid only in so far as local residents' agency of home-making is brought back into the picture. This article examines the complexity of urban transformation in China and the need for urban scholars to heed a situated, everyday perspective. It opens up the bigger question of how a sense of home and place can be and are being (re-)constructed across China, amidst numerous projects of gigantic, capital-driven urban construction.

\section{Background and Methods}

Ordos is located in the southwestern part of China's Inner Mongolia Autonomous Region. With a total area of $87,000 \mathrm{~km}^{2}$ and a total population of 1.947 million, the city is well known for its abundant natural resources, especially coal and natural gas. Ordos has a reserve of 149.6 billion tons of coal, accounting for one-sixth of China's total reserve, and a reserve of 700 billion $\mathrm{m}^{3}$ of natural gas, tantamount to $31.8 \%$ of the total proven reserve in China [24]. Ordos has hitherto been a resource-based city whose economic growth relies heavily on the state-owned energy industry [25]. For example, the coal output in Ordos grew from 22.9 million tons in 2000 to 630 million tons in 2013 [1]. The resource-driven economic boom has transformed Ordos from a relatively underdeveloped, underurbanized inland region to a high-profile, wealthy city. Involvement in coal mining or compensation from housing demolition made many residents wealthy almost overnight. The rapid accumulation of local financial assets has made it possible for the government to promote the rapid expansion of the built environment and find new spatial fixes for surplus capital [26]. In 2000, the Ordos city government decided to establish the Qingchunshan Development Zone, which was officially renamed Kangbashi New Town in 2004. Eventually, the headquarters of the local government moved from Dongsheng District, the old city centre, to Kangbashi New Town in 2006. In this context, many residents who became wealthy owing to the coal industry or compensation started 
to buy housing for living or investment. As a result, a large amount of capital flooded into the real estate industry in Kangbashi, which inflated high estate prices and in turn attracted more investment. Consequently, large-scale vacancy rates attracted media attention, resulting in the widespread discourses of "ghost towns". At present, the total area of the new town is $352 \mathrm{~km}^{2}$, while the built area is $32 \mathrm{~km}^{2}$; the number of residential neighbourhoods has augmented from 21 in 2001 to 59 in 2014. In line with the increase in residential neighbourhoods, the population of the new town has increased from 10,693 in 2011 to 49,549 in 2014 (excluding the floating population of migrant workers). The occupancy rate has also witnessed a growth since the inchoate stage of the new town development. In 2014, there were 52 residential communities in which the proportion of permanent residents exceeded fifty percent, and the overall occupancy rate was in steady growth. To sum up, although the current population of Kangbashi is much smaller than planned, our understanding of the town would be disturbingly partial, if we rely exclusively on discourses of an uninhabited ghost town.

This research mainly utilizes the methods of textual analysis and qualitative ethnography. In terms of textual analysis, this article develops a comprehensive interpretation of the media discourses on Kangbashi. We searched Baidu News, the most frequently used search engine in China, for "Kangbashi ghost city" (Kangbashi Guicheng), which returned 2470 results as of December 2016, and chose the top 100 news articles according to the news attention ranking to form a body of data for further analysis. In addition to Chinese media discourses, we collected reports published by Time magazine, The New York Times, BBC News, Al Jazeera and NIKKEI to engage with the ways in which the international media influence the construction of ghost city discourses in the Chinese domestic media. As one of the world's most influential news outlets, Al Jazeera broadcasts to more than 310 million households in more than 100 countries. It was Al Jazeera that first reported on Kangbashi New Town in November 2009 and then paid a return visit in September 2011. We analyse these two reports, titled "China's empty city" (2009) [27] and "Ordos: Boom town to ghost town" (2011) [28] in depth to trace the origin of the ghost city sentiment. Time magazine is one of the most important outlets for international readers' understanding of global issues. The report titled "Ordos, China: A Modern Ghost Town" published in Time in 2010 first gave Kangbashi the label of "ghost city", and quickly aroused international and domestic sympathy [29]. We also collected a special BBC News report titled "Ordos: The biggest ghost town in China" that further consolidated the ghost city image [30]. Finally, we collected a report titled "The Colossal Strangeness of China's Most Excellent Tourist City" published in The New York Times in 2015 [31], a few years after the ghost city trope first appeared. In order to incorporate perspectives other than those of the Western media, we also collected reports from other Asian countries, particularly two reports from NIKKEI titled "How the ghost town was tempered" (2013) [32] and "China real estate bubble is over?" (2013) [33].

This fieldwork was conducted from November 2014 to October 2016. During that period, we focused on six communities under the jurisdiction of the two main street offices of Kangbashi which attracted intensive media reports. By visiting public community centres, parks, squares and shopping malls to observe the residents' daily routine and the ways in which they interact with each other, we obtained first-hand experience of the situations of public space and everyday life practices. During these visits, we had random, informal conversations with residents who were pursuing leisure activities to develop a broad sense of their mundane socio-spatial experiences, and build rapport with potential interviewees. Formal in-depth interviews were then conducted through a snowball sampling process. In total, we interviewed 25 residents who had moved to Kangbashi at various times (see Table 1). The in-depth interviews lasted from one to three hours. The names presented in this paper are all pseudonyms. Through our earlier investigations, we found that the main inhabitants of Kangbashi are civil servants, employees in state-owned enterprises, teachers and other middle-class professionals. In this paper, we use the snowballing method to trace the practices of these middle-class components of the Kangbashi demography. We acknowledge that the home-making practices and processes of other less well-off social groups, which tend to concentrate in the fringe areas of Kangbashi, are not explored in this study. 
Table 1. Demographic profile of the participants of the interviews.

\begin{tabular}{ccccc}
\hline Pseudonyms & Gender & Age & Length of Residency in Kangbashi & Occupation \\
\hline Wang Ning & Male & 31 & 4 years & Civil servant \\
Zhu Jun & Male & 30 & 5 years & Civil servant \\
Zhang Jing & Female & 29 & 2 years & State-owned enterprise staff \\
Yang Ming & Female & 54 & 2 years & Middle school teacher \\
Li Fan & Male & 40 & 5 years & Small business man \\
Zhang Yuan & Female & 28 & 4 years & Elementary school teacher \\
Han Xian & Male & 45 & 6 years & Civil servant \\
Guo Wei & Male & 32 & 1 year & Middle school teacher \\
Chen Long & Male & 32 & 4 years & small business man \\
Li Dan & Female & 26 & 6 mouths & Elementary school teacher \\
Zhang Lu & Female & 19 & 3 years & Student \\
Liu Hua & Female & 28 & 5 years & Small business man \\
Zhang Quan & Male & 62 & 7 years & Retired civil servant \\
Chun Li & Female & 55 & 5 years & Retired civil servant \\
Li Mei & Female & 48 & 3 years & Coal enterprise manager \\
Han Dong & Male & 50 & 3 years & Coal enterprise staff \\
Xiao Feng & Male & 65 & 7 years & Retired Coal enterprise staff \\
Xiao Mei & Female & 60 & 8 years & Retired Coal enterprise staff \\
Li Feng & Male & 27 & 5 years & State-owned enterprise staff \\
Wang Fang & Female & 56 & 8 years & Small business man \\
Wen Meng & Female & 27 & 4 years & Middle school teacher \\
Qi Xin & Male & 28 & 5 years & Financial firm staff \\
Han Lin & Male & 18 & 3 years & Student \\
Yan Hua & Female & 48 & 3 years & Financial firm manager \\
Yang Yang & Male & 22 & 2 years & Student \\
\hline
\end{tabular}

The interviews began with a series of warm-up questions exploring the respondents' motives for moving to Kangbashi, places where they lived before, and basic sociodemographic status. Then, we advanced to semi-structured questions covering such topics as how they reacted to media discourses of Kangbashi as a ghost city, their own perceptions of and attitudes towards Kangbashi and the places where they had lived before, and their everyday life in Kangbashi. Our results showed that two-thirds of our respondents had moved from other parts of Ordos; two-thirds are civil servants, teachers or employees of state-owned enterprises, while one-third are self-employed businessmen and retirees; two-thirds of the families have at least two housing properties, one in Kangbashi and one in the old city; and one-third usually live separately from their spouse, while the others separately from their parents or children. Half of them had lived in Kangbashi for more than five years at the time of the interview. Most were motivated to live in Kangbashi because of the relocation of employment, the favourable living conditions, and the concentration of high-quality education resources.

We also used participant observations to complement the interviews. The participant observations were held using two methods. We took the role of audience in activities in public open spaces, including state-organized festivals and spontaneously organized grassroots leisure, in order to observe different types of public activities and residents' voluntary participation in the making of meaningful places and communities. The other method was "exploring" residents' homes. We visited five respondents' houses at their invitation and interviewed their entire family. We visited and observed residents' communities and houses in their guidance, including gardens and community shops. At the same time, we followed their daily activities in and beyond their domestic spaces, such as shopping and walking. We sought to make sense of the actual situation in Kangbashi, in contrast with media discourses, and see how residents perform and practice their sense of home and place, especially through family activities, both in their own houses and in other everyday spaces.

\section{Discourses of Ghostly Kangbashi}

In this section, we analyse the ways in which the image of a barely-inhabited Kangbashi is constructed and promulgated by the international media and how these schemes and representations are communicated to and echoed by the Chinese domestic media. We seek to problematize these 
representations of Ordos as a "ghost city" in two ways. First, we suggest that these media discourses are shaped by a preconceived geographical imagination and their portrayals of Kangbashi are selective and partial, at best. The development of new towns has occurred not solely in China, but has been common to capital accumulation through the development of the built environment in capitalist societies-capital produces "abstract spaces", while inhabitation by ordinary people gives spaces human meanings [34]. Despite this, media discourses exotify Kangbashi by mistakenly highlighting its uniqueness, with specific representational schemata that produce the widespread imagery of a "ghost city" with unhomely city experiences and landscapes. The international media are obviously disposed to depict public spaces in Kangbashi as moribund and lifeless spaces with colossal, strangely designed landscapes and empty streets devoid of urban hustle-and-bustle. BBC News, for example, wrote: "There are only two or three of us in this immense townscape. Because this is Ordos, a place that has been called the largest ghost town in China. Most of the new town buildings are empty or unfinished" [30]. The discursive rendering of the residential spaces of Kangbashi extends the rhetoric of a dead, silent and weird atmosphere even further: "We were the only guests there for the night ... We ended up spinning around and around city blocks, searching for a store selling water. Eventually we found some-but not without the feeling we had gone on a treasure hunt" [28]. Magnificent as these new cultural landscapes are, no resident goes there: "To the extent that 'the famous tourist city' attracts sightseers, they are the morbidly curious, who pilgrimage to Ordos to experience its eeriness ... the government has built a kind of Mongolian Disneyland, a city packed with kitsch monuments that evoke the heritage and heroism of life on the steppes" [31]. In many media reports on Kangbashi, the argument is complemented with photographs as evidence of objective authority, often in grey, black and other dark hues. There are very few pedestrians in the photographs, with a few construction workers repeating their boring, mechanical work against the background of large, uncompleted residential blocks.

Second, we suggest that media discourses, though reflecting on the massive capitalization of urban space, neglected that the unhomely aspects of ghost towns, produced by state-enforced urbanism, and individuals' engagement in home-making are not mutually exclusive. These media discourses describe the new phenomenon of urban development in China that emerged in recent years when local officials began to expand the city space to develop new town projects and became dependent on the sale of land to developers, which led to the emergence of large-scale commercial housing clusters $[27,28]$. Such discourses suggest that what caused the cities and society to build them was not the demand for affordable housing but a desire for multiplying economic assets [28]. Therefore, in media discourses, the great Chinese building boom caused China's overbuilt and underpopulated instant cities [31], with unsold flats, unlet shops, and empty office blocks [30]. Al Jazeera described the reason as follows: "If building a road pumped up GDP, then building a whole city would really propel GDP growth to unknown heights" [28]. While critiquing the problems that arise from China's overinvestment in and overaccumulation of the built environment is warranted, it is a great leap to ignore the human role in negotiating rapid socio-spatial changes. People living in Kangbashi were portrayed as forced to migrate due to aggressive top-down social engineering [31]. Media discourses only noticed farmers who became instantly rich after selling their land, moved to Kangbashi, and then had nothing to do except gather to play cards and mah-jongg outside their new houses [31]. In the media discourses, the residents are negative recipients without the agency to negotiate their own living conditions. We argue that the unsustainable pattern of real estate economy does not mean that Kangbashi is a barely-inhabited ghost city that is home to comically few people. In addition to the real estate economy, the development path, dominated by the local government has also made Kangbashi a political, cultural and educational centre that attracts the middle class, such as teachers, civil servants and workers, to become its main residents. Their social, economic, and cultural capital help them easily and quickly make the city a new home. The international media discourses are not based on a nuanced excavation of the lived experiences of the actual people inhabiting Kangbashi and thus cannot grasp the vernacular practices, routines and meanings enacted by the residents. Home-making 
is not determined linearly by the macropolitical economic structure, but is rather a bottom-up process overdetermined by political economic contexts but contingent on everyday practices [16].

Although an unhomely, ghostly atmosphere is only a partial description of Kangbashi, some Chinese domestic media and other Asian media have nonetheless chosen uncritically to reproduce the ghostly place image and continue to perpetuate negative narratives of Kangbashi [35]. Of the 100 Chinese news reports that received the most attention, 69 mentioned Western media reports or mainly adopted those reports as bases of their own arguments. Some of these reports began with Western media coverage or simply and unsparingly translated the contents of the Western reports as their own content [36]. These media that questioned the local government-led urbanization [32] and the economic model that relies on real estate development [33] primarily paraphrased the perspectives of international media. For example, some reports are entitled "China's ghost cities that have no signs of life" [37], "Does China really need so many houses? Ghost cities are desolate" [38], and "The Ordos Kangbashi ghost city spectacle: to buy clothes, you have to go $20 \mathrm{~km}$ away" [39]. With this framing, the media deduce that Kangbashi has lost its vitality and potential for future development. Yet, there do exist some media reports delivering more nuanced pictures of Kangbashi, in terms of the growth of its employment base, improvement of infrastructure and the increasing occupancy rate $[40,41]$. This is a divergence from dominant and admittedly monotone reporting of ghost towns.

\section{Residents' Experience of Home in Kangbashi}

In this section, we will elaborate residents' agency of home-making that media reports have neglected, and how residents, through their everyday practices, maintain a delicate equilibrium between old and new homes, as persistent connections with the old city centre feed positively into the liveability of the new town. It is this everyday mobility that make residents settle down in Kangbashi. Meanwhile, by anchoring their daily lives in multiple types and scales of urban spaces, residents have gradually cultivated a sense of home in Kangbashi and destigmatize the ghost city in discursive and embodied ways to consolidate this sense of place.

\subsection{Connecting "New Home" and "Old Home": Home-Making through Translocal Connection}

The majority of the residents of Kangbashi migrated from other parts of Ordos in pursuit of better work opportunities or public resources; therefore, building a new home in Kangbashi is their first priority. Thus, residential communities of Kangbashi should not simply be derogated as uninhabited places, as residents' agency in home-making looms large in these newly established communities. The community infrastructure was sophisticatedly developed, community property management serviced $80 \%$ communities, and a health service centre had been built in almost every community to facilitate medical care for the residents. The residents had convenient access to daily necessities such as water, power and garbage collection. In the context of increasing mobility in modern society, home is often associated with more than one place and does not necessarily exist in a fixed location [21]. Instead, mobility has become central to the process of home-making [42]. We suggest that after moving to Kangbashi, residents generally find that connections between the new home and the former home helped facilitate their sense of home in the new environment. This connection is reflected in their mobility between the new town and the old city, and the nostalgia for the tranquil, idyllic life in the old city. In fact, the old city feeds positively into the liveability of the new town.

First, in the early stages of residence in Kangbashi, the new town served its specific purposes while also being well-connected enough for them to go swiftly back to the old town. For example, Han Dong is a senior engineer working in a large coal enterprise in Dongsheng, and his wife is the human resources manager of the same company. Before moving to Kangbashi, they lived with his son and Han's parents in a three-bedroom apartment in Dongsheng district, the old city centre $25 \mathrm{~km}$ from Kangbashi. It is generally acknowledged that a high-quality education for children is of great importance, so many parents prefer to buy a flat in a school catchment zone [43]. To consolidate the social sustainability of Kangbashi and attract more residents, the municipal government provides 
residents in Kangbashi with privileged access to high-quality education. As a result, many schools, such as the municipal key middle schools and kindergartens, the Ordos Institute of Technology (the only higher education institution in Ordos), and Ordos's top-ranking high school have moved to Kangbashi. To access good educational resources, Han Dong bought a three-bedroom apartment near his son's middle school. Since then, the couple have lived with their son in their new home for the sake of his education, commuting between Kangbashi and Dongsheng from Monday to Friday and returning to their former home in Dongsheng on weekends and school vacations, where Han Dong's parents remain to take care of the family living. Han Dong describes the lifestyle of moving between two homes in his community:

Unscrupulous media said here is a ghost city, no one lives here, because they do not understand the patterns of our lives. Take our community, for example; almost everyone here has a car. On the weekend, a third of the cars in the underground garage will be gone. These media deliberately come here on weekends to count people. How could that be?

While this type of commuting can be understood as a way of negotiation in response to the new town's incomplete functions, it simultaneously affects the "feeling" of the place. In contrast to rural-to-urban migrants who tend to assign positive associations to old homes and negative associations to destination cities [44], Kangbashi residents are mainly constituted by the urban middle class, thus presenting a very different scenario. Through regular and patterned mobility between the two homes, the two homes both became an important part of the family's life. Due to the functional difference between the two homes, the above-mentioned couple attributed different meanings to Dongsheng and Kangbashi. In the new home, they maintain the family's income stability and cultivate the family's future promises through commuting and accommodating the son's need for education. To live in Kangbashi, they gradually found that moving between two homes had become a means to negotiate the pressure in the old city. Han Dong explained that although his son had entered college in Beijing, he and his wife still live in Kangbashi every week:
My wife and I basically go back to the home in Kangbashi every day as usual, because we want to have a good rest after work. Here (in his new home in Kangbashi), I feel very quiet and relaxed. If I suddenly receive a call from a colleague in Dongsheng who invites me to a banquet, I usually don't want to attend and reply that I have gone back to Kangbashi, and because of the distance, he won't keep pressuring me to come. But if I am in Dongsheng, they'll absolutely mind if you refuse.

This statement show that the residents interviewed have no sense of struggle and ambivalence, but felt comfortable living in Kangbashi. This mobility enables residents to find the most comfortable lifestyle after the move, and finally settle in Kangbashi. When people continually attribute meaning to a particular place, it will transform from a simple container to a home-place associated with belonging and identity [45]. Home is not just a place for settlement but also carries positive emotions [46]. Through the family practice of translocal mobility, a clear division has emerged between the functions and meanings of two homes. The old home in Dongsheng functions to gain income and maintain the social network of relatives and friends, while the new home in Kangbashi has become a home-place to escape the pressure of work and experience tranquillity and relaxation. The bottom-up practices of residents thus find converging points with the top-down drive of the government.

Nostalgia for their former ways of life bring new opportunities to connect the old home and the new home. Kangbashi reminds some residents of the simple and comfortable experience of living in a small town or village, and the experience of living in the old home has been transplanted in creative ways to the new home. Xiao Mei, for example, lived with four family members in a two-story villa with flowerbeds on two sides. Xiao Mei was born in Dongsheng and witnessed Ordos developing from a village to a modern city. As Freeman et al. [47] notes, "garden and gardening play important roles in home making". After moving to the new home in Kangbashi, Xiao Mei transformed the two flowerbeds into a garden for vegetables and fruits that provides the family with healthy food. 
After dinner, Xiao Mei and her family took a walk in their community and talked to their neighbours; often, they exchange vegetables as a token of neighbourly rapport. Xiao Mei said:

Every day when I grow my own vegetables in Kangbashi, it always reminds me of the time living in the bungalow in Dongsheng when it was still a small village. The happiest experience at that time was to take care of the fruits and vegetables by myself. Later, because of the urban development, the bungalow was demolished, and we moved to a commercial housing building that no longer offered space for planting. After moving here, in my garden or my neighbours' garden, we meet each other almost every day to communicate life experiences about how to plant these vegetables well.

The old home is not necessarily the space immediately before the relocation; it may be the memory and yearning for a better life from the past. Thus, gardening not only expresses residents' pursuit of closeness to nature [48], but also creates an emotional connection to the place from which they originally came. This connection is not only physical but also represents the return of the spiritual ascription. The community is actually of vital energy, combining natural impulses and human inhabitation. In the daily life of residents, home-making activities not only strengthen the bond between the people and the place where they live [17], but also offer opportunities for connection between their new and old homes.

\subsection{Everyday Habitation in Kangbashi}

In this section, we continue to explore how residents in Kangbashi anchor their everyday inhabitation in positive meanings, and reproduce a sense of home by means of various practices. First, we have found that the commercial and leisure spaces of Kangbashi meet the residents' daily needs in multiple ways. There are 12 high-end hotels, four shopping centres, and 1479 outlets composed of various restaurants and bars. Residents have easy access to leisure and recreation facilities in public spaces, because 31 different parks and squares with various ornamental plants are distributed throughout the spatial fabrics of the new town. These urban facilities serve as a material basis for home-making and facilitate local residents' connection to the new environment [22].

Although Kangbashi's commerce is not as atrophied as it is described in the media discourse, the commercial spaces and options of goods to purchase are relatively limited in comparison to other areas in Ordos. At present, most of Kangbashi's dining choices are concentrated in a food court that provides many types of foods and is crowded at every mealtime. Despite this, many residents are keen to explore new venues and opportunities for consumption that are not yet familiar, and constantly expand their own cognitive maps of living. In fact, everyday consumption practices do provide a channel for residents to become familiar with Kangbashi. Li Feng, a 27-year-old worker at a state-owned enterprise, explained that he was tired of eating in the food court and often felt pleasantly surprised when he found a new restaurant that offers local cuisine. He admitted that he gradually became familiar with Kangbashi through food consumption. Meanwhile, frequent interaction in community shops has become a part of daily life for the residents, and a sense of home arises from being addressed by name when entering a grocery shop [49] and receiving assiduous and thoughtful service. Liu Hua, a young female resident, said that she goes every day to the shop behind her apartment, in which she converses with the shop owner, whom she calls sister Fang (Fang Jie), as a means of recreation and to anchor her intimacy with other community residents.

We basically buy food here and are already very familiar with each other [the shop owner]. The people in this community like to come and chat with her about daily chores after work. Her store is like a community news station; what happens in the community can be known here. She's just like our sister, and she even helps me look after my daughter when I am not able to do it in some cases. I feel very relieved.

Our fieldwork also revealed many episodes of mutual help in community stores, such as the sharing of information about job opportunities and housing and even temporarily helping familiar 
customers by taking care of their children, which signals that an unwitting home-making is in process, despite limited commercial space.

Second, in contrast to the image of moribund and lifeless streets, various kinds of daily leisure activities, such as walking, dancing and singing, are vivid in Kangbashi's public space. When they first moved to Kangbashi, residents could not completely and felicitously use the facilities, and considered the urban squares and parks ostentatious landscapes. However, as they adapted to the new environment through daily leisure activities, residents gradually became familiar with these public landscapes and could accurately identify them by their names and specific locations. For example, some people said that they habitually walk along a relatively fixed route to trace the urban landscapes that they perceive as meaningful. Zhang Jing, a company employee describes her after-work leisure activities as follows:
Almost every day, I will listen to the music while walking along the street after work. Starting from my apartment, I will go through Mulun Ulan Lake... then cross over Genghis Khan Bridge into the Prairie Art Cultural Park, sometimes go to the front of the government building after Double Horse Square, passing the green square, and then return. When I walk in the city, I feel so relaxed and I am free from any disturbance.

This expression not only objectively depicts the residents' habitual organization of everyday life, but also shows that entertainment and leisure activities have reinforced their belonging to the city of Kangbashi as a whole. Moreover, everyday life practices have made residents familiar with every corner of the city to the extent that they can quickly identify places by their names and locations. Moreover, spontaneous singing and dancing in public spaces are also evident. They write their own songs, and many of the lyrics describe the amenities of Kangbashi, and some of them publicly celebrate residents' belonging and attachment to the city. Xiao Feng, one of the singing leaders, is fascinated with singing the praises of a happy life in Kangbashi, as exemplified by the following lyrics:

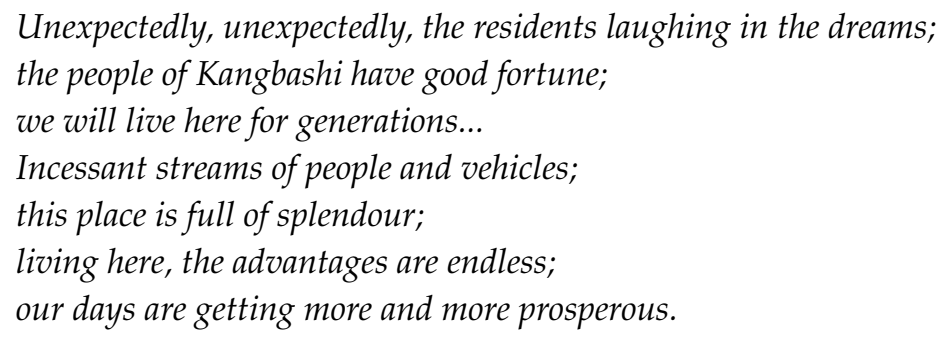

The meaning of Kangbashi as their home is embedded in a context of relaxation, security and comfort. In this sense, we can draw a picture of home as something beyond the house, but embedded in the spatial-temporal punctuations of the whole new town.

In response to "the ghost city" discourse, some residents would consciously reject this stigma, as their sense of home was questioned by outsider perspectives. One feature of home is its capacity to provide privacy and security for individuals, so people's perception of home, regardless of emotional or material definitions, is often characterized by a clear territory and boundaries that distinguish them from "others" [16]. As Rose suggests, the sense of home includes the idea of defining oneself in opposition to "others". People living in Kangbashi already viewed it as their home in emotional charged ways. Thus, residents will defend their home when they encounter untrue and negative comments about it. Many residents sincerely treat Kangbashi as a meaningful place in need of protection and avoid any comments that devaluate it. For example, 32-year-old Guo Wei told us of an experience that made him very angry:

Once I travelled by train, and I heard a stranger telling two girls that if they arrived at Kangbashi, they must be careful because few people lived there. There were no people at night, and residential buildings seem to be haunted, so it was called a ghost town. After hearing that, the two girls were very scared. This made me quite angry, and I immediately exposed his lies and told them that 
Kangbashi is a modern city with beautiful scenery. If I see this kind of person in the new town, I will definitely drive him out.

Therefore, the psychological boundaries of "home" are created by fending off the infringements and criticism of "others". In addition to correcting misconceptions, residents also destigmatize the "ghost city" by performing their place identity through collective dancing. Some residents engage in collective dancing in the parks where tourists tend to concentrate. For example, 55-year-old Chun Li was singing loudly and dancing confidently in a performance for tourists when we conducted our research at a public park. Subsequently, she explained:

Aren't they curious about what a ghost city looks like and what kind of people are willing to stay here? We'll dance to show them and let them know how happy we are! The so-called empty city is actually not empty at all, and the ghost city has no ghosts.

\section{Conclusions}

This article has reviewed and problematized media discourses, and examined residents' practices and experiences of Kangbashi New Town as home. In this study, we have shown that a ghost town is not an exotic phenomenon unique to Chinese urbanism in the 21st century, but comparable to the production of urban spaces in a capitalist economic system [50]. We must critically examine the media's assessment of the economic and social sustainability of new town development in China. The descriptions of ghost cities in media discourses cause problems of exoticising urban spaces in China, stigmatizing the lives of those living in the town, and downplaying the agency of residents. It fits a continual pattern of both domestic and international media essentially failing to take seriously anything that appears "abnormal" in China. Although there are undeniable problems like housing vacancies and development bubbles in new town development, we are sceptical of the inclination to crown the new towns with unhomely images and equating them with the label of a desolate "ghost city". The lopsided focus on the political and economic dynamics of (over)investment and municipal finance perpetuates a view of Kangbashi that erases the lived experiences of the residents. The new towns, however, are not homogeneous or unitary urban spaces, but meet residents' demands for housing conditions, environment, education, and communal life in specific ways.

This article provides a critique of comments on China's new town development which solely draws from the macro-political and economic perspective, arguing that the sustainability of the new town not only hinges on urban development patterns or the durability of the cycles of capital accumulation. More importantly, sustainability is very much about whether the people living in it can handle the new socio-spatial patterning of life, and form communities and attachments to the place. In the rapid process of China's urbanization, more attention should be paid to how residents create a home and foster a sense of belonging and identity in a new town allegedly devoid of human-place bonds and active inhabitation.

From our ethnographic work and the interviews, we identified how residents create home and foster a sense of home and place belonging when they are implicated in their everyday inhabitation of urban spaces in Kangbashi. Despite increasing population growth, Kangbashi is nevertheless an underpopulated urban region, and has not thrived to the extent that the municipal authorities once envisaged. Nevertheless, a process is now clearly underway, even in the most infamous of "ghost cities", through which the residents of new cities are (re-)constructing senses of home, and that this is strongly suggestive of the prospect that, over the medium to long term, these cities-in-waiting will undoubtedly undergo profound social changes and place-making processes. Reid and Beilin [17] have argued that home represents a source of continuity. Our data reveals that continuity manifests itself most evidently in the mobility between old homes and new homes. Following Cristoforetti et al. [45], we argue that everyday practices, such as consumption in community shops, gardening, and strolling in the parks, extend the sense of home beyond the private space to the surrounding public spaces and landscapes. As to residents' perceptions, Kangbashi is appreciated for 
being quiet, spacious, distant, slow-paced, reminiscent of simpler "rural" life, and amenable to ad hoc social interaction. Above all, residents are not passive recipients of the built environment and media discourses, but capable of manipulating local resources and practices to construct their own sense of home, through mundane and embodied practices.

Acknowledgments: This work was supported by a Key Project of the National Natural Science Foundation of China (NSFC Grant No. 41630635).

Author Contributions: Duo Yin wrote the major parts of the paper, collected the data, and undertook analyses. Junxi Qian refined the arguments of the paper and edited the language and grammar. Hong Zhu contributed to designing the conceptual framework and methodology of the article.

Conflicts of Interest: The authors declare no conflict of interest.

\section{References}

1. Woodworth, M.D.; Wallace, J.L. Seeing ghosts: Parsing China's "ghost city" controversy. Urban Geogr. 2017, 38, 1-12. [CrossRef]

2. Sorace, C.; Hurst, W. China's phantom urbanisation and the pathology of ghost cities. J. Contemp. Asia 2016, 46, 304-322. [CrossRef]

3. He, G.; Mol, A.P.; Lu, Y. Wasted cities in urbanizing China. Environ. Dev. 2016, 18, 2-13. [CrossRef]

4. Shepard, W. Ghost Cities of China: The Story of Cities without People in the World's Most Populated Country; Zed Books: London, UK, 2015.

5. Jin, X.; Long, Y.; Sun, W.; Lu, Y.; Yang, X.; Tang, J. Evaluating cities' vitality and identifying ghost cities in China with emerging geographical data. Cities 2017, 63, 98-109. [CrossRef]

6. Long, Y. Redefining Chinese city system with emerging new data. Appl. Geogr. 2016, 75, 36-48. [CrossRef]

7. Chen, X.; Wang, L.; Kundu, R. Localizing the production of global cities: A comparison of new town developments around Shanghai and Kolkata. City Community 2009, 8, 433-465. [CrossRef]

8. Wang, L.; Kundu, R.; Chen, X. Building for what and whom? New town development as planned suburbanization in China and India. Suburb. Glob. Soc. 2010, 10, 319-345. [CrossRef]

9. Chi, G.; Liu, Y.; Wu, Z.; Wu, H. Ghost cities analysis based on positioning data in China. arXiv, 2015. Available online: https://arxiv.org/abs/1510.08505(accessed on 4 November 2017).

10. Xiao, L.; Qiu, Q.; Gao, L. Chinese Housing reform and social sustainability: Evidence from post-reform home ownership. Sustainability 2016, 10, 1053. [CrossRef]

11. Brickell, K. 'Mapping' and 'doing' critical geographies of home. Prog. Hum. Geogr. 2011, 36, 225-244. [CrossRef]

12. Nowicka, M. Mobile locations: Construction of home in a group of mobile transnational professionals. Glob. Netw. 2007, 7, 69-86. [CrossRef]

13. Suda, K. A room of one's own: Highly educated migrants' strategies for creating a home in Guangzhou. Popul. Space Place 2016, 22, 146-157. [CrossRef]

14. Elizabeth, S.; Pantzar, M.; Watson, M. The Dynamics of Social Practice: Everyday Life and How it Changes; SAGE: London, UK, 2012.

15. Reckwitz, A. Toward a theory of social practices: A development in culturalist theorizing. Eur. J. Soc. Theory 2002, 5, 243-263. [CrossRef]

16. Blunt, A.; Dowling, R. Home; Routledge: Abingdon, UK, 2006.

17. Reid, K.; Beilin, R. Making the landscape "home": Narratives of bushfire and place in Australia. Geoforum 2015, 58, 95-103. [CrossRef]

18. Meijering, L.; Lager, D. Home-making of older Antillean migrants in the Netherlands. Ageing Soc. 2014, 34, 859-875. [CrossRef] [PubMed]

19. Massey, D. A place called home? New Form. 1992, 17, 3-15.

20. Kochan, D. Home is where I lay down my hat? The complexities and functions of home for internal migrants in contemporary China. Geoforum 2016, 71, 21-32. [CrossRef] 
21. Ralph, D.; Staeheli, L.A. Home and migration: Mobilities, belongings and identities. Geogr. Compass 2011, 5, 517-530. [CrossRef]

22. Lucas, S.; Purkayastha, B. “Where is home?" Here and there: Transnational experiences of home among Canadian migrants in the United States. GeoJournal 2007, 68, 243-251. [CrossRef]

23. Boccagni, P. What's in a (migrant) house? Changing domestic spaces, the negotiation of belonging and home-making in ecuadorian migration. Hous. Theory Soc. 2014, 31, 277-293. [CrossRef]

24. Woodworth, M.D. Ordos municipality: A market-era resource boomtown. Cities 2015, 43, 115-132. [CrossRef]

25. Woodworth, M.D. Frontier boomtown urbanism in Ordos, Inner Mongolia autonomous region. Cross Curr. 2012, 1, 74-101. [CrossRef]

26. Harvey, D.; Braun, B. Justice, Nature and the Geography of Difference; Blackwell: Oxford, UK, 1996.

27. China's Empty City. Available online: http://www.aljazeera.com/news/asia-pacific/2009/11/ 2009111061722672521.html (accessed on 24 June 2017).

28. Ordos: Boom Town to Ghost Town. Available online: http://www.aljazeera.com/blogs/asia/2011/09/ 70656.html (accessed on 24 June 2017).

29. Ordos, China: A Modern Ghost Town. Available online: http://content.time.com/time/photogallery/0, 29307,1975397_2094492,00.html (accessed on 24 June 2017).

30. Ordos: The Biggest Ghost Town in China. Available online: http://www.economist.com/node/18775303 (accessed on 24 June 2017).

31. The Colossal Strangeness of Chinas Most Excellent Tourist City. Available online: https:/ /www.nytimes. com/2015/03/06/t-magazine/ordos-china-tourist-city.html (accessed on 24 June 2017).

32. How the Ghost Town Was Tempered. Available online: https://cn.nikkei.com/china/ceconomy/631220130820.html (accessed on 4 September 2017).

33. China Real Estate Bubble Is Over? Available online: https://cn.nikkei.com/china/ceconomy/9565-20140612. html (accessed on 4 September 2017).

34. Harvey, D. Spaces of Capital: Towards a Critical Geography; Routledge: New York, NY, USA, 2001.

35. Pain, R. Globalized fear? Towards an emotional geopolitics. Prog. Hum. Geogr. 2009, 33, 466-486. [CrossRef]

36. Double Crisis under the Mirage of Erdos Ghost Town. Available online: http:/ finance.people.com.cn/n/ 2013/0901/c1004-22763641-2.html (accessed on 24 June 2017).

37. China's Ghost Cities That Have No Signs of Life. Available online: http://society.nen.com.cn/society/396/ 3474896.shtml (accessed on 24 June 2017).

38. Does China Really Need So Many Houses? Ghost Cities Are Desolate. Available online: http://www.sohu. com/a/75452189_268229 (accessed on 24 June 2017).

39. The Ordos Kangbashi Ghost City Spectacle: To Buy Clothes You Have to Go $20 \mathrm{~km}$. Available online: http:/ / www.dfdaily.com/html/33/2011/3/1/574117.shtml (accessed on 24 June 2017).

40. Erdos: Three Pillar Industries Gradually Formed. “Ghost town” Is False. Available online: http:/ / news. southcn.com/z/2013-09/13/content_79118344.htm (accessed on 4 September 2017).

41. Inner Mongolia Ordos: “Ghost Town” Kangbashi Is a Flourishing Place. Available online: http://news.21cn. com/caiji/roll1/a/2017/0701/11/32437577.shtml (accessed on 4 September 2017).

42. Liu, C. Food practices, gendered intimacy and family life in contemporary Guangzhou. Gend. Place Cult. 2017, 24, 97-107. [CrossRef]

43. Wu, Q.; Zhang, X.; Waley, P. Jiaoyufication: When gentrification goes to school in the Chinese inner city. Urban Stud. 2016, 53, 3510-3526. [CrossRef]

44. Kochan, D. (Re) placing migrants' mobility: A multi-method approach to integrating space and mobility in the study of migration. Migr. Stud. 2016, 2, 215-237. [CrossRef]

45. Cristoforetti, A.; Gennai, F.; Rodeschini, G. Home sweet home: The emotional construction of places. J. Aging Stud. 2011, 25, 225-232. [CrossRef]

46. Feng, D.; Breitung, W.; Zhu, H. Creating and defending concepts of home in suburban Guangzhou. Eurasian Geogr. Econ. 2014, 55, 381-403. [CrossRef]

47. Freeman, C.; Dickinson, K.J.M.; Porter, S.; van Heezik, Y. “My garden is an expression of me": Exploring householders' relationships with their gardens. J. Environ. Psychol. 2012, 32, 135-143. [CrossRef] 
48. Mazumdar, S.; Mazumdar, S. Immigrant home gardens: Places of religion, culture, ecology, and family. Landsc. Urban Plan. 2012, 105, 258-265. [CrossRef]

49. Cloutier-Fisher, D.; Harvey, J. Home beyond the house: Experiences of place in an evolving retirement community. J. Environ. Psychol. 2009, 29, 246-255. [CrossRef]

50. Lefebvre, H. The Production of Space; Blackwell: Oxford, UK, 1991.

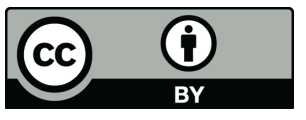

(C) 2017 by the authors. Licensee MDPI, Basel, Switzerland. This article is an open access article distributed under the terms and conditions of the Creative Commons Attribution (CC BY) license (http://creativecommons.org/licenses/by/4.0/). 